\title{
Regulation, Knowledge Transfer, and Forestry Policy Implementation: Different Strokes for Different Folks?
}

\author{
Roje S. Gootee \\ Natural Resource Sciences, Washington State University \\ 120 Johnson Hall, Pullman, WA 99164-6410, USA \\ Tel: 1-509-335-6166 E-mail: rushcreek@hevanet.com \\ Edward P. Weber (Corresponding author) \\ School of Environmental and Public Affairs, University of Nevada-Las Vegas \\ 4505 S. Maryland Parkway, Box 454030 \\ Las Vegas, NV 89154-4030, USA
}

Tel: 1-702-895-4440Ｅ-mail: Edward.weber@unlv.edu

Keith Blatner

Natural Resource Sciences, Washington State University

115 Johnson Hall, Pullman, WA 99164-6410, USA

Tel: 1-509-335-6166 E-mail: blatner@wsu.edu

Matt Carroll

Natural Resource Sciences, Washington State University

183 Johnson Hall, Pullman, WA 99164-6410, USA

Tel: 1-509-335-2235_E-mail: carroll@wsu.edu

David Baumgartner

Natural Resource Sciences, Washington State University

131 Johnson Hall, Pullman, WA 99164-6410, USA

Tel: 1-509-335-2963Ｅ-mail: baumgartner@wsu.edu

Received: October 18, $2011 \quad$ Accepted: November 16, $2011 \quad$ Published: February 1, 2012

doi:10.5539/sar.v1n1p55

URL: http://dx.doi.org/10.5539/sar.v1n1p55

\begin{abstract}
Knowledge transfers from the public to the private sector about the substance and necessity of regulatory rules are critical for effective regulatory compliance. With groups of professionals that share specialized training the overall problems are minimized. Yet what happens when regulators contend with non-professionals? Using a case of forestry policy in Washington State we find that professional-to-professional exchanges are relatively effective, but that non-professional forest owners were less responsive, which reduced the effectiveness of the knowledge transfer and program compliance. We also find that one way to overcome this implementation barrier is to have regulators use an adult-based learning method.
\end{abstract}

Keywords: Regulation, Knowledge transfer, Forestry policy, Adult learning, Ways of knowing, Policy implementation 


\section{Introduction}

By definition, a private forest owner's ability to provide good forest management is linked to appropriate knowledge about forest ecology and stewardship practices. Additionally, where private forest practices are regulated by government, forest owners need to understand not only the regulatory policies, but also the rationale behind regulations; otherwise they are less likely to willingly comply with regulatory directives (Creighton \& Baumgartner, 2005, 197). Consequently, in order to facilitate effective forest management natural resource professionals advising and/or otherwise regulating private forest owners must have the capacity to not only convey such knowledge, but to do so in a manner in which it is accepted and applied by those being regulated. Traditionally, especially in regulatory arenas defined by science and technical issues, the passage of knowledge from the public to the private sector has been treated as a fairly simple, technical transfer of a set of facts, rules, and policies across the public-private boundary (Nicolini et al., 2003, 6). Success requires the creation of a common language, computer or information technology compatibility, a common set of training guidelines and procedures, and so on (Carlile, 2002). The emphasis is on sending information, or finding ways to standardize or make compatible methods of communication to facilitate the transfer of knowledge from one participant or organization to the next, and to identify the barriers that slow this process or the structural components of the regulatory relationship that might speed this process (Podolny \& Page, 1998).

Such an approach to knowledge transfer makes sense if the senders and receivers of such knowledge share an occupational profession. Within each separate group of professional economists, lawyers, engineers, or silviculturalists (foresters), for example, individuals have been shown to adhere and respond to professionally defined career-based incentives for advancement, and to be shaped profoundly by their specialized training (Mosher, 1982). The net result is that professional groups tend to direct their attention to, and give more credence to, certain types of information, while also showing a preference for distinctive problem recognition and problem-solving methods (Katzmann, 1980; Scott, 1998). Clearly, for many regulatory realms that primarily, if almost exclusively, require interactions between similarly trained experts on both sides of the regulatory puzzle (e.g., securities regulation/securities law; finance and tax regulations), this approach to knowledge transfer is adequate.

However, there are many regulatory arenas where the professionals (experts) in government agencies are not always complemented by similarly trained professionals in the private sector. What happens then? How do regulators ensure that their knowledge is accepted and applied when the regulated community may be responding to different cues, perhaps more social than technical in nature, or perhaps closely related to their own on-the-ground decision-making experiences, as they decide what constitutes valid knowledge for problem solving purposes? Moreover, what happens to the knowledge transfer dynamic when the regulated community is not reasonably monolithic, or homogeneous, in its composition? Do regulators need to adapt their approach to the knowledge transfer puzzle in such cases?

These questions have become more central to policy and regulatory debates in recent years with the growth of private-public partnerships and other collaborative governance arrangements that regularly and integrally engage a broad variety of publics and professionals in policy decision-making and implementation processes (Bingham \& O'Leary, 2008; Sirianni, 2009; Weber, 2003). As well, we have learned more about distinctive, value laden "ways of knowing" that directly affect people's perspectives on information, problems and solutions (Feldman et al., 2006), and as researchers have started to understand knowledge and knowledge transfer from a "pragmatic view of knowledge" that treats it as "localized, embedded, and invested in practice" (Carlile, 2002) (Note 1). It is not enough from this perspective to highlight differences between participants, for sometimes that will only heighten the difficulties of transferring knowledge. Rather, there is a need to recognize the connections between knowledge and practice, or the premise that what people and organizations know is deeply embedded in what they practice. This view of knowledge has a "situated" dimension to it, in that knowledge must be understood in the context of practice that is situated in a geographic setting, a particular point in time, or within a particular set of social relationships (Nicolini et al., 2003). In other words, in order to get effective regulatory compliance in some, perhaps many cases, regulatory professionals must understand the individuals and business/landowners they are regulating as well as the technical specifics found in the scientific and regulatory rationales for particular rules (Cartmell et al., 2006; Downing \& Finley, 2005).

To help forest policymakers and regulators better understand the dynamics of knowledge transfer, we examine the process of knowledge exchange between private forest owners and natural resource management professionals (regulators) in the State of Washington. The research is part of a larger study of Washington's innovative "Alternate Plan option," (Note 2) a policy instrument developed by the State to render its Forest Practices Rules (WAC 222) more responsive to individual properties and owners. Study participants were 
asked to describe and compare their various knowledge sources, and to discuss which types they most preferred and why. The private forest owners of importance to the segment of the study discussed in this paper belonged to two groups -"professional" non-industrial private forest (NIPF) owners and smaller "non-professional" non-industrial private forest (NIPF) owners. The variation within the regulated community allowed us to examine the differences, if any, in the way that professionals and non-professionals approached the transfer of knowledge from regulators and the broader implications from any such differences.

Our findings confirm that forestry professionals, whether public or private, hold similar views toward knowledge and credible sources of knowledge, and that this helped to facilitate a relatively easy exchange of knowledge across the public-private organizational boundaries as well as the application of that knowledge to forest practices by the private "professional" foresters. Yet we also discovered that "non-professional" NIPF owners viewed knowledge differently than professional foresters, and tended not to use the same criteria as professionals to determine the credibility of information. Non-professionals relied more heavily on social cues, as opposed to scientific validity, and the degree to which they felt their own experientially based forest expertise was respected as part of the conversation over whether and how the state's regulators would permit them to develop an Alternate Plan for their forest property. For this part of the regulated community "knowledge is practice." In short, this group plays by a different set of rules that require acknowledgement on the part of natural resource managers if the knowledge they are imparting is to be heard, accepted and applied to the public problem at hand. Put differently, the disjuncture in the approaches to knowledge reduced the effectiveness of the knowledge transfer to non-professionals because Washington State regulators did not correctly understand what many forest owners needed from their knowledge providers.

\section{Study Area and Research Method}

We studied forest owners throughout the State of Washington who had considered or participated in the Alternate Plan program. The Alternate Plan option enables a forest owner to request departures from any of the prescriptive regulations that arise from the state's Forest Practices and Forest Practices Rules, as long as the forest owner can demonstrate to the satisfaction of a team of state natural resource professionals that the owner's proposal can be expected to produce a level of ecological protection at least equivalent to that obtainable under the prescriptive rules. The forest owner, often assisted by one or more privately hired consultants, works collaboratively with land management agency experts to finalize the accepted provisions of the Alternate Plan. The program requires extensive communication and knowledge exchange between forest owners, consultants, and agency professionals, and consequently provides an excellent forum for studying the process of knowledge transfer between professionals and non-professionals. Private forest owners receive information and regulatory supervision from the State Department of Natural Resources, Department of Ecology, and Department of Fish and Wildlife. In cases involving federally listed threatened or endangered species, the United States Fish and Wildlife Service or National Marine Fisheries Service may also become involved. On sites where sensitive soils are a concern, the federal Natural Resource Conservation Service may participate. Forest owners also often turn to the Washington State University Extension Service, forest ownership organizations, and peer networks for information and advice.

Forests and forest management are integral to the culture and economy of Washington State. Forests comprise approximately half of the state's land base, and about $42 \%$ of the $22 \mathrm{M}$ total forested acres are privately owned (Washington Department of Natural Resources, 2005, Erickson \& Rinehart, 2005). Of the privately held forests, about 1.3 million acres are owned by Washington's 34 Native American tribes, another $2.5 \mathrm{M}$ acres are owned by the industrial forest ownership sector (Erickson \& Rinehart, 2005; Mason, 2007). The remaining approximately 5.5 million acres are owned by an estimated 215,000 non-industrial private forest (NIPF) owners (Washington Department of Natural Resources, 2001; Rogers \& Cooke, 2009).

We conducted an inductive, qualitative study, collecting data through in-depth interviews with 109 diverse stakeholders involved in the design, administration, and use of the Alternate Plan program. As is typical in inductive studies, the interview group was selected on the basis of theoretical rather than statistical sampling. Theoretical sampling was purposive, rather than random or statistically selective. Interviewees were selected by means of chain referral based upon their knowledge or experience in the subject under study. The sample size was determined by the emerging data: new interviewees were sought until additional interviews yield only repetitive, rather than new, data. The interview group included forest owners, policy advisors, state and federal land management agency personnel, natural resource consultants, forest business consultants, and special interest group representatives. Most interviews lasted at least two hours, but a few lasted as long as three or four. Most all study participants were interviewed in person, although six were interviewed by telephone at their request. All interviewees were promised anonymity. The interview process was ongoing from August 2004 through June 
2007, with follow-up phone calls taking place into 2008. The interviews were semi-structured to ensure that each covered the same material. As part of their discussion of their overall experience with and perceptions of the Alternate Plan program, interviewees were asked to discuss their information sources, their perceptions of and reactions toward those sources, and their reasons for choosing or rejecting the information offered.

The interview data were analyzed using the constant comparison technique (Glaser \& Strauss, 1999, 101-116). This technique enabled the researchers to progressively compare the data from each interview with all of the previous ones. Emergent themes were identified and coded (Clarke, 2005), and related quotations and observations of patterns were compiled in a process described by Maykut and Morehouse (1994) as the discovery stage.

\section{The Variation in Contexts: Professionals versus Non-Professionals}

Diverse regulated communities can pose a challenge for regulatory officials. In the case of private forestlands in Washington State, there is a major difference in the types of NIPF forest owners government officials must deal with. On one side there are the professional IPF's and NIPFs, while on the other are the non-professional NIPFs. The distinct contexts within which these forest owners operate can be characterized along three dimensions-degree of integration into the policy network, educational/professional backgrounds, and perception of personal efficacy in the regulatory process.

Professional IPF's and NIPFs in Washington State are well integrated into the forestry management policy network. They are typically long-term players in the forest ownership arena. Many professional NIPF's have followed in the footsteps of other family members engaged in forestry management. In other words, they belong to a multi-generational stewardship and management tradition of private forests that has been passed down along with the professional expectations associated with effective management practices and interaction with public officials. They are more likely to be members of the Washington Farm Forestry Association, the primary statewide organization representing non-industrial forest owners. Some have personally engaged in political activities such as lobbying government officials and attending forest management conferences involving both private and public officials. Many thus have well- established working relationships with existing and former regulators as well as other IPF and NIPF professionals.

By contrast, non-professional NIPFs are usually on the outside looking in at the policy network. They rarely come from an established lineage of private forest owners and typically have limited contact with forestry agency officials as well as with other NIPFs, professional or otherwise.

The same differences abound when it comes to educational/professional backgrounds. Whereas professional NIPFs typically have specific, high level technical training in natural resource and forestry sciences and practices, non-professional NIPFs come from diverse educational and professional backgrounds that tend to have no direct relationship to forestry or natural resource management. Given this, professional NIPFs are advantaged because they speak the same language as their regulatory overseers who share their intensive training and focus on all things forestry, while non-professionals are at a distinct disadvantage given their lack of familiarity with concepts, terms, acronyms, and practices. Moreover, given that non-professional NIPFs almost always manage their lands for multiple goals (e.g., recreation, nature-based retreat or haven, as well as forestry) and pursue other full-time professions, most NIPFs we interviewed agree that there are definite limits on the ability of non-professionals to overcome this disadvantage. Finally, professional NIPFs tend to identify themselves as members of a recognizable occupational group or community, in this case, forestry professionals, while non-professionals, given their diversity, do not.

These key differences among professionals and non-professionals factor into forest owners' sense of their own personal efficacy in the regulatory process. As might be expected, professional NIPFs are experienced and therefore can more easily adapt to the requirements of regulatory planning and implementation exercises, and possess a high degree of confidence in their own "expert" ability to evaluate knowledge, plans, and regulatory directives. Non-professionals, on the other hand, are uncomfortable and inexperienced in the regulatory planning and implementation spheres, and although they may feel a close personal attachment to their forest they tend to have a low degree of confidence in evaluating regulatory information and directives on their own. As well, non-professional NIPFs experience a low sense of efficacy, given that weak integration into the policy network and the lack of forestry background leaves them discouraged and feeling out of their depths when they do interact with government officials. Moreover, part of this discouragement and diminished efficacy stems from the fact that non-professionals encounter considerably higher costs in their attempts to gather and verify information vis-à-vis professional NIPFs. 


\subsection{Results and Discussion: Evaluating, Accepting and Applying Knowledge: Different Strokes for Different Folks}

The descriptive differences in the professional versus non-professional contexts alone are not of significance. The critical significance lies in the connections between the context, decision and problem-solving practices, and, ultimately, outcomes (Katzmann, 1980; Khademian, 1992). With respect to professional and non-professional NIPFs in Washington State, the differences in context are correlated to distinctive approaches to decision-making as they relate to receiving and incorporating forestry management knowledge from regulatory officials. The professional NIPFs rely heavily on what we call a "technical, merit-based" approach to how knowledge from regulators is treated, while non-professionals adopt a radically different approach grounded in social relationships and a strong sensitivity to the manner in which regulators treat them when discussing forestry management plans and regulatory options. The variance in approaches directly affect whether the knowledge regulators are seeking to transfer is heard, understood, accepted, and applied to public problems by private forest owners.

Professional NIPFs, by contrast, approach knowledge in much the same way as their professional counterparts in the regulatory agencies. They focus tightly on the credibility, or merit, of the science employed for a particular decision or plan and accept criteria such as "professional reputation", "scientific credibility", and "peer review" (personal interviews). If the plan is firmly grounded in good science, then the likelihood increases that professional NIPFs will understand, accept, and apply the new knowledge. As one large, industrial forest owner notes: "We rarely get sideways with the agency professionals, and, in fact, we find them generally easy to communicate with and work with" (personal interview, 2/10/05). Similarly, professional NIPFs tend to treat knowledge providers - the person delivering the information--in the same way. What is the "technical" reputation of the provider? Do they have the appropriate professional or technical pedigree(s) in terms of education and experience to be credible? In this way, professional NIPFs do not lean heavily on personal relationships. Instead they treat providers as interchangeable as long as they meet the technical standards associated with the provisions of credible, science-based information.

Non-professional NIPFs, on the other hand, generally respect science and know that it is necessary to many regulatory decisions governing forest management (personal interviews). Yet they also seek a more level playing field in which experiential knowledge related to their particular forest is treated as a valuable component of decision-making, particularly when the science being used is derived from models rife with uncertainty or from unique, non-local landscapes that do not clearly correspond with the management and ecosystem realities of their own forest. For example, an owner of riverfront forest property states:

These new riparian regulations have just been a nightmare. We're really limited in what we can do in terms of timber harvest on our place now, even though my wife's family has been here for generations and we've always managed the place sustainably. There wouldn't even be a riparian forest still here if we hadn't always taken pretty good care of it (personal interview, 10/10/05).

A non-professional NIPF expresses this broader sentiment with respect to science: "Science-based agencies won't take social risks, they won't admit that their science isn't always accurate," while another laments that "I get frustrated over scientists who have tunnel vision. They can't see the whole picture, they don't know my history or the environmental history of my piece of land" (personal interviews, 10/4/04 and 11/9/04). This difference in approach also leaves agency "professionals" frustrated. As one puts it, "the science speaks for itself. I don't really understand why so many of them the non-professional NIPFs want to keep arguing about it" (personal interview, 3/10/05). Another adds, "We're going where the science takes us. I'd like to see more landowners understanding the science and pleased about using it It's hard to get most of the small forest owners to accept it" (personal interview, 2/16/05).

At the same time, non-professionals rely heavily on personal social relationships and individualized trust when deciding whether the knowledge on offer is appropriate. Thus, their subjective impressions of the person or institution delivering it becomes critical, especially the perceived attitude and intent of the individual(s) delivering the information. For example, "most NIPF's are very wary of the agencies and do not particularly trust them to be objective. Our Cooperative Extension forester, though, was great. He really helped us" (personal interview, 9/17/04). Others are concerned that too many agency professionals in the forestry arena "know a lot about fish and forests, but not so much about people" (personal interview, 9/17/06). This means that knowledge providers are not interchangeable based on their technical competency. Instead, providers are far more likely to meet with success in transferring knowledge to the extent they appreciate that "it's all about relationships," especially personal, trust-based relationships (personal interviews, $12 / 22 / 06 ; 3 / 10 / 05$; see also Weber \& 
Khademian 2008). Thus it matters when agency professionals give the impression that "forest owners are bad," or that in-house agency scientists "are getting too self-important," or, on a more positive note, whether "they really wanted me to be successful in my forest. I wish more of the people from the agencies were like that" (personal interviews, $10 / 4 / 04 ; 12 / 21 / 05 ; 4 / 6 / 05$ ).

If no such personal relationship exists, whether because of scarce agency resources or otherwise, then the tendency of non-professional NIPFs is to rely on other sources for knowledge and advice (although relative to professional NIPFs, these networks are weak and small). Given this, it then becomes important for regulators to make the attempt to better understand how non-professionals are linked together so that they can build positive, trust-based relationships with critical influencers within the non-professional network, leaving the influencers to positively impact the rest of the network. In some instances these influencers may be professional forestry consultants, but for the subset of NIPF owners who cannot afford or prefer not to work with a consultant, the influencers are likely to be other, trusted non-professional NIPF owners.

Another key difference in the decision on whether to accept and apply knowledge from regulators is grounded in the approach to knowledge assessment. Both professionals and non-professionals expressed frustration with the tendency of forestry agencies in Washington State to give inconsistent advice on management recommendations and regulatory interpretations, thereby making it imperative that they verify and reconcile government information and recommendations. Given their own educational backgrounds/expertise and strong sense of efficacy, professionals tend toward self assessment and/or a reliance on other professionals' assessments of knowledge. But non-professionals, perhaps because of mistrust as well as a weak sense of efficacy and lack of forestry training, tend to go much further. They commonly check the veracity of the knowledge being imparted across a much broader range of sources. Chief among these are Washington State University Cooperative Extension (WSU Extension), private consultants, and informal networks. As one non-professional NIPF noted, "I always hope I'm getting good guidance from a particular agency employee, but I really like having my forestry consultant as a backup. I know he's looking out for me" (interview, 4/20/06). Others in this category said they prefer to rely on information from their informal personal networks than on scientific information from an institution or another professional. This was particularly the case if they did not have a strong, positive working relationship with the regulatory agencies or its employee representatives (personal interviews, 9/04 through 5/07).

Finally, non-professionals focus on the amount of empathy regulators display toward them and their personal situation. Of critical importance are questions such as: Do government-based knowledge providers treat such private forest owners with respect given their non-professional status and unique problem sets that involve more than forestry as a management goal for the land? Do regulators make a reasonable effort to show non-professional NIPFs how a new rule or plan can benefit them and their land? Is knowledge exchange a two-way street in which both science and experiential knowledge are integral to decision-making and in which landowners' concerns, whether economic, aesthetic, or ecological, are given a fair hearing? Few were tolerant of a professional whom they did not believe respected them, their personal situation, or their experience. As one non-professional forest owner who had won awards for good forest management said, "It offends me that they seem to assume I'm likely to mismanage my land without their direct supervision. It's almost as though they expect that I don't want to or know how to do the right thing" (personal interview, 10/05/04). In another case, a landowner frustrated with a particular agency employee said, "That guy was the weakest link throughout all of this effort to design a timber harvest on his property. Finally, though, we got to the right people and we could hardly believe what a difference that made" (personal interview, 10/10/05). In other cases, non-professional NIPFs noted that that they sought communications with agency professionals that clearly signaled "respect, respect, respect" (personal interview, 10/4/04), whether it was in the style of communication-"talk with us, not at us" (personal interview, 3/10/05), or in the appreciation for the different decision dynamics confronting a forest landowner/manager as opposed to agency regulators and scientists.

There's a crucial difference between the way most forest owners and most scientists make decisions. For forest owners and operators, adaptive management is essential or they wouldn't be able to successfully make a living. They need to be able to make decisions and take action quickly. Pure scientists, though, are distanced from temporal pressure and the causes and effects of decisions. They can view scientific rigor as the prime decision point (personal interview, 11/23/04).

In short, failure to recognize the importance of this empathy dynamic for non-professionals lessens the likelihood that knowledge will be transferred and applied. 


\subsection{The Regulatory Approach, Adult Learning Theory, and the Knowledge Transfer Problem}

The differences in the context--degree of integration, educational backgrounds, and sense of efficacy-and in the evaluative criteria, or decision-making style used to decipher and decide which knowledge is worthy of being transferred and used in forest management practices are clear. The problem, as Creighton and Baumgartner (2005), Katzmann (1980), Khademian (1992), and others have found, is that the differences in evaluative criteria can also have direct implications for policy and management outcomes. Our findings agree, yet add an important additional element to the policy implementation mix - we found that there is a match, or correspondence, between the decision styles in the regulated community and the approach to the regulated community by regulatory officials. In cases where the regulatory interaction is between agency and private sector "professional" NIPFs, knowledge is more likely to be transferred successfully because regulatory policies and the rationale that drives them are more likely to be well understood. Both regulators and professional NIPFs operate according to the same decision criteria described above-science is key and both sides of the regulatory transaction speak the same language and are part of the same recognizable occupational community of natural resource professionals.

Core elements of an effective atmosphere for adult learning are inherent in such horizontal, peer-to-peer, transactions. These core elements include a shared cognitive background, mutual understanding, mutual interpersonal respect, and a readiness for a multi-directional dialogue receptive to the knowledge and opinions of all who are party to the exchange of information (Vella, 1994; Merriam et al., 2007). We found that regulators consciously or unconsciously employed techniques that enhance adult learning when interacting with this group of professional private foresters. As noted by Daniels and Walker (2001) in their work on collaborative learning in natural resource policy settings, "adults bring more experience, less patience, and little tolerance for being 'taught'; they want to learn actively while they are working on the issues that are important to them. They need to be co-learners or peers much more than pupils" (79). Regulators tended to set the stage for effective adult learning by embracing a dynamic of reciprocity in which regulatory 'experts' respected the professional NIPF 'learners' prior knowledge, offering a peer-to-peer, horizontal (as opposed to hierarchical) learning dynamic (Keen \& Mahanty, 2006; Vella, 1994). The peer-to-peer interaction accepted that a successful "cycle of discovery, integration, application, and transmission of new knowledge is dynamic and non-hierarchical" (McGrath, 2006, 5), and led, according to those interviewed, to a learning atmosphere in which they experienced 'membership' status and a high degree of collegial respect within the professional network. This peer status also translated into a greater willingness on the part of regulators to give greater credibility to professionals' practical forestry management experiences, the type of pragmatic, contextually oriented subject material that adult learners typically desire (Extension Committee on Organization and Policy, 1985), in cases where the science and empirical outcomes clashed (Knowles, 1984; Rogoff, 1984).

The congruence between the professionals', both regulators and NIPFs, decision styles, along with the regulators' provision of a respectful atmosphere conducive to effective adult learning, led to higher satisfaction on the part of the professional private forest landowners and often a greater willingness to comply with regulatory directives (less resistance), hence more effective forest management/plan implementation. From this perspective there is no knowledge transfer conundrum and policy implementation success improves because of it.

A substantial problem often surfaces, however, when the interaction is with non-professional forest landowners, not because they are naturally resistant to new knowledge and/or regulatory requirements and management plans, but because the knowledge exchange process between regulatory professionals and non-professional, layperson NIPF forest owners often fails to embody a positive atmosphere for effective adult learning. The problem is exacerbated by the fact that, for non-professional forest owners, the degree and type of necessary learning is often far more difficult to achieve. For a professional forest owner, any necessary new learning about forest stewardship principles or forest regulations is likely to be comparatively minor and incremental, since the professional owners begin their new learning from an already high platform of prior knowledge. Non-professional forest owners, by contrast, often begin from a relatively low or even non-existent platform of prior relevant knowledge. Many of them must therefore engage in a much more challenging process, one which typically involves a steep, long learning curve and may also involve a need for 'transformative learning' (Mezirow, 1978; Cranton, 2006) that substantially changes their understanding of their fundamental relationship with their land. Instead of adapting their knowledge transfer approach to accommodate the different learning context and decision-making style of the non-professional forest owners group, however, regulatory professionals tended to forge ahead with their same technical, merit-based "scientific professional" style of information delivery and failed to cultivate the core elements associated with a successful adult learning environment. First, regulators did not offer the potential for peer-to-peer interaction and/or relationships 
mimicking the more typical close, neighborly relationships of value to this group. Instead they fostered a more conventional, hierarchical professional/non-professional relationship which reinforced the intellectual distance, hence separateness between regulators and regulated. As Mellow (2005) and Clover (2002) have previously noted, this is a recipe for dissatisfaction and resistance. The hierarchical 'expert to non-expert' approach creates an inevitable tension between the presumption of the professional 'experts' that formal education and science are most relevant, and the opposing presumption on the part of many non-professionals that their informal education and experience with their forestland deserves a similarly high level of respect and credence (Merriam et al., 2007). We found that this apparent lack of respect from certain natural resource professionals was especially objectionable to non-professional forest owners who had earned awards for good forest management, or who were accustomed to receiving a high level of professional courtesy and respect in other job settings.

Second, many of the regulatory professionals bypassed critical early phases of the learning cycle (Kolb, 1984; Daniels \& Walker, 2001) by failing to adequately explain or otherwise demonstrate the relevance of new concepts or regulations to non-professional forest owners before requiring implementation. Since "knowledge acquisition is a gradual process (MacEachren, 1992), and "the order in which learning occurs is essential to its effectiveness" (Vella, 1994, as quoted in Daniels \& Walker, 2001), this type of omission hampers the knowledge acceptance and application process.

Third, regulators typically failed to demonstrate empathy, or "situational cognition" in their interactions with the non-professionals. Situational cognition means that adults want evidence that the knowledge provider relates to and understands their circumstances "from the inside out" (Rogoff, 1984). Because adults are reluctant to engage with educators who do not appear to be situationally cognitive, knowledge is unlikely to be adopted unless conveyed through personnel and media attuned to its recipients (Keen \& Mahanty, 2006). In fact, this agrees with Kittredge (2004), who found that many forest owners gravitate strongly toward empathetic knowledge providers, rather than those who simply try to inform, teach, or regulate them.

The fact that many natural resource professionals are unfamiliar with and do not employ precepts of effective adult education is not surprising. The available research and information linking adult learning theory to environmental contexts is so widely dispersed in interdisciplinary literature that it is difficult for researchers or practitioners to locate and conceptualize (Meyer, 2006). Furthermore, despite the fact that their work frequently involves the need to educate stakeholders about environmental concepts, the formal training of natural resource professionals focuses on ecology and typically omits any discussion of educational theory. As a result, although well-informed about ecological concepts, many natural resource professionals are not well equipped to convey those concepts to the public. The overall effect in the case of non-professional NIPFs in Washington State was a poor understanding of regulatory policies, misconceptions about forest ecology and management, and disillusionment with many of the professionals and institutions advising them. Importantly, and perhaps unsurprisingly, these outcomes of the knowledge transfer process led to greater resistance to the knowledge on offer, which ultimately resulted in less effective implementation of forest management regulations and plans (Gootee, 2009). Given the fact that the vast majority of forest owners-over 90,000 in Washington alone-fall into this category of non-professional NIPF's, the failure to take account of their different decision-making style is likely to have significant negative consequences for forest health, while also increasing citizen distrust of government agencies more generally (which makes future knowledge transfers that much more difficult). Similar outcomes may be expected to follow the continued emergence of collaborative environmental governance opportunities, wherein professionals and non-professionals must necessarily be closely engaged in an ongoing process of information transfer (Rickenbach et al., 2004).

\section{Conclusion}

This research highlights the significant variation in the approach to knowledge within the world of Washington State forest management policy. The variation means that the transfer of knowledge and the tendency to more willingly comply with the new forest program in question went relatively smoothly between agency forestry professionals and private sector forestry professionals. Such was not the case, however, when the transfer of knowledge involved agency professionals to non-professionals. A key reason that this latter case did not work well is that the non-professional receivers of information relied much more on socially grounded, value laden "ways of knowing" and the context of their own practice-based experiences, rather than the "science" of forestry preferred and emphasized by agency professionals. The difficulties of knowledge transfer and policy compliance were further compounded by the way in which Washington State forestry officials approached non-professional forest owners. These owners were treated to a conventional, hierarchical expert/non-expert relationship instead of a more appropriate adult learning approach offering a peer-to-peer, horizontal (as opposed to hierarchical) learning dynamic. 
The problem with the hierarchical approach today, of course, is that scholars and many others now recognize that society's view of science and scientists is in transition (Ozawa, 1991; Kuhn, 1996). Forest management, once primarily a technical matter of improving commodity production, now encompasses far more diverse social interests (Smith, 1997). As well, society and scientists are increasingly aware that scientific discovery is a dynamic, open-ended process wherein any current knowledge is not necessarily conclusive (Jasanoff \& Martello, 2004). Consequently, the public is increasingly unwilling to view natural resource professionals as omniscient regarding appropriate environmental management strategies, and is often resentful of professionals who attempt to retain hierarchical "expert/non-expert" relationships with stakeholders (Luckert, 2006; Winter et al., 2004).

All of which leads back to the importance of adult learning theory as a potential key tool for regulators faced with the challenge of multiple approaches to knowledge within the regulated community. More studies are needed that test the ability of adult learning theories, properly applied, to overcome the barriers faced by regulators in such situations. Another implication of this research is that regulatory agencies might find greater success to the extent they employ professionals with both adequate science credentials and considerable training in the social sciences, including more specifically, communications, education, dispute resolution, economics, sociology, psychology, and/ or political science. Familiarity with the fundamentals of transformative learning and adult education would substantially improve the preparedness of natural resource professionals for their critically important role as public educators by helping them recognize the limitations and risks associated with the conventional, hierarchical 'expert-to-non-expert' paradigm of information transfer.

\section{References}

Belanger, Paul. (2003). Learning environments and environmental education. New Directions for Adult and Continuing Education, 99(Fall 2003), 79-88. http://dx.doi.org/10.1002/ace.112

Bingham, Lisa, \& Rosemary O'Leary. (Eds.) (2008). Big Ideas in Collaborative Public Management. New York: M.E. Sharpe.

Carlile, Paul R. (2002). A Pragmatic View of Knowledge and Boundaries: Boundary Objects in New Product Development. Organization Science, 13(4), 442-455. http://dx.doi.org/10.1287/orsc.13.4.442.2953

Cartmell, D. Dwayne II, Chandra L. Orr, \& Danna B. Kelemen. (2006). Effectively disseminating information to limited-scale landowners in the urban/rural interface. Journal of Extension, 44(1), 11. Accessed online on 11/08/2006 at http://www.joe.org/joe2006february/a5.shtml

Clarke, Adele E. (2005). Situational Analysis: Grounded Theory after the Postmodern Turn. Thousand Oaks, CA: Sage Publications.

Clover, Darlene. (2002). Environmental adult education. Adult Learning, 13(2/3), 2-6.

Cranton, Patricia. (2006). Understanding and Promoting Transformative Learning: A Guide for Educators of Adults (2nd Edition). San Francisco, CA: Jossey-Bass.

Creighton, Janean H., \& David M. Baumgartner. (2005). Washington State's forest regulations: family forest owners' understanding and opinions. Western Journal of Applied Forestry, 20(3), 192-198.

Daniels, Steven E., \& Gregg B. Walker. (2001). Working through Environmental Conflict: The Collaborative Learning Approach. Westport, CT: Praeger Publishers.

Downing, Adam K., \& James C. Finley (2005). Private forest landowners: What they want in an educational program. Journal of Extension, 43(1), 9. Accessed online on 11/08/2006 at http://www.joe.org/joe/2005february/rb4.shtml

Erickson, Ara, \& James Rinehart. (2005). Private forest ownership in Washington State. Unpublished manuscript from Saving Washington's Working Forest Land Base forum, University of Washington, College of Forest Resources (November).

Feinstein, Benjamin C. (2004). Learning and transformation in the context of Hawaiian traditional ecological knowledge. Adult Education Quarterly, 54(2), 105-120. http://dx.doi.org/10.1177/0741713603260275

Feldman, Martha, Anne Khademian, Helen Ingram, \& Anne Schneider. (2006). Ways of Knowing and Inclusive $\begin{array}{lllll}\text { Management Practices. } & \text { Public Administration } & \text { Review. } & 66, & \end{array}$ http://dx.doi.org/10.1111/j.1540-6210.2006.00669.x

Finger, M. (1989). Environmental adult education from the perspective of the adult learner. Convergence, 22(4), 25-32. 
Glaser, Barney G., \& Anselm L. Strauss. (1999). The Discovery of Grounded Theory: Strategies for Qualitative Research. New York: Aldine de Gruyter.

Haugen, Caitlin S. (2006). Environmental adult educator training: suggestions for effective practice. Convergence, 39(4), 91-106.

Hill, Lilian H., \& Darlene E. Clover. (Eds.) (2003). Environmental Adult Education: Ecological Learning, Theory, and Practice for Socioenvironmental Change. Issue 99 of the Jossey-Bass quarterly report series New Directions for Adult Learning and Education. San Francisco, CA: Jossey-Bass.

Jasanoff, Sheila, \& Marybeth L. Martello. (Eds.) (2004). Earthly Politics: Local and Global in Environmental Governance. Cambridge, MA: MIT Press.

Kapoor, Dip. (2003). Environmental popular education and indigenous social movements in India. In Environmental Adult Education: Ecological Learning, Theory, and Practice for Socioenvironmental Change. Issue 99 of the Jossey-Bass quarterly report series New Directions for Adult Learning and Education. San Francisco, CA: Jossey-Bass: 47-57.

Katzmann, Robert. (1980). Federal Trade Commission. In J. Q. Wilson (ed.), The Politics of Regulation. New York: Basic Books: 152-187.

Keen, Meg, \& Sango Mahanty. (2006). Learning in sustainable natural resources management: Challenges and opportunities in the Pacific. Society and Natural Resources, 19, 497-513. http://dx.doi.org/10.1080/08941920600663896

Khademian, Anne M. (1992). The SEC and Capital Market Regulation: The Politics of Expertise. Pittsburgh, PA: University of Pittsburgh Press.

Kittredge, David B. (2004). Extension/outreach implications for America's family forest owners. Journal of Forestry, 102(7), 15-18.

Kohm, Kathryn A., \& Jerry F. Franklin. (Eds.) (1997). Creating a Forestry for the 21st Century: The Science of Ecosystem Management. Washington, D.C.: Island Press.

Kolb, David A. (1984). Experiential Learning: Experience as the Source of Learning and Development. Prentice-Hall: Englewood Cliffs, NJ.

Knowles, Malcolm S. (1980). The Modern Practice of Adult Learning: From Pedagogy to Androgogy (2nd Ed.). Follet: Chicago, IL.

Knowles, Malcolm S. (1984). Androgogy in Action: Applying Modern Principles of Adult Learning. San Francisco, CA: Jossey-Bass.

Kuhn, Thomas S. (1996). The Structure of Scientific Revolutions (3rd Edition). Chicago, IL: The University of Chicago Press.

Luckert, Martin K. (2006). Has the myth of the omnipotent forester become the reality of the impotent forester? Journal of Forestry, 104(6), 299-306.

MacEachren, Alan M. (1992). Application of environmental learning theory to spatial knowledge acquisition from maps. Annals of the Association of American Geographers, 82(2), 245-274. http://dx.doi.org/10.1111/j.1467-8306.1992.tb01907.x

Magill, Daniel J., David W. McGill, \& Rory F. Fraser. (2004). Refining outreach to woodland owners in West Virginia - preferred topics and assistance methods. Journal of Extension, 42(4), Accessed online on 11/8/2006 at http://www.joe.org/joe/2004august/rb5.shtml

Mason, Larry. (2007). "Changing private forest management intensities: Western Washington.” Discussion Paper 6, Final Report, Future of Washington's Forest and Forest Industries Study. Seattle, WA: University of Washington.

McGrath, Daniel M. (2006). The scholarship of application. Journal of Extension, 44(2), Accessed online on 02/02/2007 at http://www.joe.org/joe/2006april/a8.shtml

Mellow, Muriel. (2005). The work of professionals: Doing the gemeinschaft-gesellschaft gavotte. Rural Sociology, 70(1), 50-69. http://dx.doi.org/10.1526/0036011053294637

Merriam, Sharan B., Rosemary S. Caffarella, \& Lisa M. Baumgartner. (2007). Learning in Adulthood: A Comprehensive Guide. (3rd Edition). San Francisco, CA: Jossey-Bass. 
Meyers, Ronald B. (2006). Environmental learning: reflections on practice, research, and theory. Environmental Education Research, 12(3-4), 459-470. http://dx.doi.org/10.1080/13504620600799216

Mezirow, Jack. (1978). Perspective transformation. Adult Education, 28, 100-110. http://dx.doi.org/10.1177/074171367802800202

Nicolini, Davide, Silvia Gherardi, \& Dvora Yanow. (eds.) (2003). Knowing in Organizations: A Practice Based Approach. Armonk, NY: M.E. Sharpe.

Ozawa, Connie. (1991). Recasting Science: Consensus-Based Procedures in Public Policy Making. Boulder, CO: Westview.

Podolny, Joe, \& Karen Page. (1998). Network forms of Organization. Annual Review of Sociology, 24, 57-76. http://dx.doi.org/10.1146/annurev.soc.24.1.57

Rickenbach, Mark G., John C. Bliss, \& A. Scott Reed. (2004). Collaboratives, cooperation, and private forest ownership patterns: implications for voluntary protection of biological diversity. Small-scale Forest Economics, Management and Policy, 3(1), 69-83.

Rogoff, B. L. J. (1984). Everyday Cognition: Its Development and Social Context. Cambridge, MA: Harvard University Press.

Scott, James C. (1998). Seeing Like a State: How Certain Schemes to Improve the Human Condition Have Failed. New Haven and London: Yale University Press.

Sirianni, Carmen. (2009). Investing in Democracy: Engaging Citizens in Collaborative Governance. Washington, D.C.: The Brookings Institution.

Smith, Gordon R. (1997). Making Decisions in a Complex and Dynamic World. In Creating a Forestry for the 21st Century: The Science of Ecosystem Management. Kathryn A. Kohm and Jerry F. Franklin (Eds.). Washington, D.C.: Island Press: 419-435.

Sumner, Jennifer. (2008). Protecting and promoting indigenous knowledge; environmental adult education and organic agriculture. Studies in the Education of Adults, 40(2), 1-10.

Taylor, Edward W. (2008). Transformative learning theory. New Dimensions for Adult and Continuing Education, 119, 5-15.

United States Department of Agriculture (USDA). (2000). 1997 resources inventory (Revised). Accessed online on 02/03/2007 at http://www.nhq.arcs.usda.gov/NRI/1997/

Vella, Jane. (1994). Learning to Listen: Learning to Teach. San Francisco, CA: Jossey-Bass.Walter, Pierre (2007). Adult learning in new social movements: environmental protest and the struggle for the Clayoquot Sound rainforest. Adult Education Quarterly 57(3), 248-263. http://dx.doi.org/10.1177/0741713606297444

Weber, Edward P. (2003). Bringing Society Back In: Grassroots Ecosystem Management, Accountability, and Sustainable Communities. Cambridge, MA: MIT Press.

Weber, Edward P., \& Anne M. Khademian. (2008). Wicked Problems, Knowledge Challenges, and Collaborative Capacity Builders in Network Settings. Public Administration Review, 68(2), 334-349. http://dx.doi.org/10.1111/j.1540-6210.2007.00866.x

Winter, Greg, Christine A. Vogt, \& Sarah McCaffrey. (2004). Examining social trust in fuels management strategies. Journal of Forestry, 102(6), 8-16.

\section{Notes}

Note 1. Scott (1998) develops a similar concept that he terms "metis"--a wide array of practical skills and acquired intelligence developed in response to the dynamic environment (313).

Note 2. The Alternate Plan option (WA RCW 76.09; 76.13; and WAC 222-12-040) permits forest owners to suggest management alternatives that differ from the State's prescriptive Forest Practices Rules (WAC 222), if the alternative can be expected to result in equivalent or better levels of protection. 